\title{
COMENTÁRIOS DIRETOS E INDIRETOS NA REVISÃO TEXTUAL UTILIZANDO FERRAMENTAS DIGITAIS
}

\author{
MARINA KRISCAUTZKY LAXAGUE \\ Universidad Nacional Autónoma de México. Doctora en Ciencias con especialidad \\ en investigación educativa, área de Psicolingüística, por el Departamento de \\ Investigaciones Educativas del Centro de Investigación y Estudios Avanzados del \\ Instituto Politécnico Nacional de México. Docente en la Facultad de Filosofía y Letras, \\ Universidad Nacional Autónoma de México, y en la Universidad de La Plata, Argentina. \\ ORCID 0000-0003-3489-1537 mkriscau@unam.mx.
}

\section{MIRUNA KAYANO GENOINO}

Escola da Vila. Mestre em Escrita e Alfabetização pela Universidade de La Plata, Argentina. Especialista em Alfabetização pelo Centro de Formação da Escola da Vila em São Paulo, Brasil. Pedagoga formada pela Universidade de São Paulo USP. Coordenadora de Ensino Fundamental da Escola da Vila, São Paulo, Brasil. ORCID 0000-0002-7375-4028. E-mail: mirunagenoino@gmail.com 


\section{COMENTÁRIOS DIRETOS E INDIRETOS NA REVISÃO TEXTUAL UTILIZANDO FERRAMENTAS DIGITAIS}

Neste trabalho apresentamos os resultados de uma investigação realizada no âmbito do Mestrado em Escrita e Alfabetização da Universidade de La Plata, Argentina, sobre um dos processos envolvidos na construção do conhecimento sobre a escrita: revisar um texto para melhorá-lo. Especificamente abordase a revisão do texto de outro e comentá-lo por escrito através de ferramentas digitais, uma vez que a tecnologia é atualmente uma parte fundamental das interações escritas que ocorrem socialmente. A investigação foi realizada com meninos e meninas de 7 anos de idade que frequentavam o $2^{\circ}$ ano do Ensino Fundamental de uma escola particular de São Paulo, Brasil. Essas crianças já dominavam o princípio alfabético do sistema de escrita e estavam em condições de refletir sobre a composição escrita, lendo sozinhos e comentando por escrito. Nossas questões principais de pesquisa foram compreender qual conteúdo linguístico as crianças poderiam selecionar para comentar os textos, quais estratégias de comunicação usariam com a ferramenta digital proposta e como seriam as trocas orais no processo de revisão dos textos. Entre os principais resultados, destacamos a análise dos diferentes espaços de texto em que os alunos decidem escrever seus comentários sobre o texto dos colegas, proposto para leitura, a realização de diferentes tipos de comentários que chamaremos de diretos e indiretos, e seu impacto no texto e, finalmente, a importância das trocas orais entre os pares de autores e comentaristas dos textos para entender os diferentes aprendizados que foram desenvolvidos na proposta didática.

Palavras-chave: Revisão textual. Ferramentas digitais. Interação. Processo de escrita.

\section{DIRECT AND INDIRECT COMMENTS IN TEXTUAL REVIEW USING DIGITAL TOOLS}

In this paper we present the results of an research carried out within the scope of the Master in Writing and Literacy at the University of La Plata, Argentina, on one of the processes involved in the construction of knowledge about writing: revising a text to improve it. Specifically, it addresses the revision of another's text and comments on it in writing using digital tools, since technology is currently a fundamental part of written interactions that occur socially. The research was carried out with 7-year-old boys and girls who attended the 2nd year of elementary school at a private school in São Paulo, Brazil. These children already mastered the alphabetic principle of the writing system and were in a position to reflect on the written composition, reading alone and comment by writing. Our main research questions were to understand what linguistic content children would select to comment on texts, which communication strategies they would use with the proposed digital tool and how oral exchanges would be in the text review process. Among the main results, we highlight the analysis of the different text spaces in which students decide to write their comments on the text of their colleagues, proposed for reading, making different types of comments that we will call direct and indirect, and their impact on the text. Finally, the importance of oral exchanges between authors and commentators of the texts to understand the different learnings that were developed in the didactic proposal.

Keywords: Textual review. Digital tools. Interaction. Writing process.

\section{plurais}




\section{COMENTARIOS DIRECTOS E INDIRECTOS EN LA REVISIÓN TEXTUAL UTILIZANDO HERRAMIENTAS DIGITALES}

En este trabajo presentamos resultados de una investigación realizada en el marco de la Maestría de Escritura y Alfabetización de la Universidad de La Plata, Argentina, acerca de uno de los procesos involucrados en la construcción de conocimientos acerca de la escritura: revisar un texto para mejorarlo. En este caso, revisar un texto ajeno y comentarlo por escrito a través de herramientas digitales ya que, en la actualidad, la tecnología es parte fundamental de los intercambios escritos que suceden socialmente. La investigación se realizó con niños y niñas de 7 años que cursaban el $2^{\circ}$ grado de primaria de una escuela privada de São Paulo, Brasil. Estos niños ya dominaban el principio alfabético del sistema de escritura, por lo que estaban en condiciones de reflexionar acerca de la composición escrita leyendo por sí mismos y comentando por escrito. Nuestras principales preguntas de investigación eran comprender cuáles contenidos lingüísticos utilizarían los niños para comentar los textos, qué estrategias de comunicación podrían llevar a cabo con la herramienta digital propuesta y cómo serían los intercambios orales en el proceso de revisión de los textos. Entre los principales resultados destacamos el análisis de los diferentes espacios textuales donde los alumnos deciden escribir sus comentarios sobre el texto ajeno que se les ha propuesto para la lectura; la realización de diferentes tipos de comentarios que llamaremos directos e indirectos y sus impactos en el texto; y finalmente la importancia de los intercambios orales entre las parejas de autores y comentaristas de los textos para comprender los diferentes aprendizajes que se desarrollaron en la propuesta didáctica.

Palabras clave: Revisión textual. Herramientas digitales. Interacción. Processo de escritura.

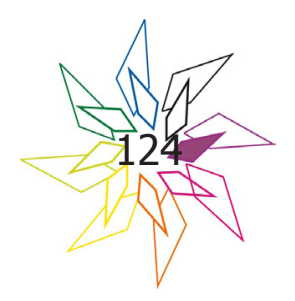




\title{
COMENTÁRIOS DIRETOS E INDIRETOS NA REVISÃO TEXTUAL ATRAVÉS DE FERRAMENTAS DIGITAIS
}

\section{Introdução}

\begin{abstract}
Quase sempre, ao se criticar esse gosto da palavra oca, da verbosidade, em nossa educação, se diz dela que seu pecado é ser "teórica". Identifica-se assim, absurdamente, teoria com verbalismo. De teoria, na verdade, precisamos nós. De teoria que implica numa inserção na realidade, num contato analítico com o existente, para comprová-lo, para vivê-lo e vivê-lo plenamente, praticamente. Neste sentido é que teorizar é contemplar (FREIRE, 1996, p. 101).
\end{abstract}

Contemplar a realidade de um processo de aprendizagem, torná-la objeto de estudo, colocá-la no centro de uma preocupação consciente com os possíveis caminhos e encruzilhadas das crianças em busca de que aprendam mais, e cada vez melhor, deve ser um olhar de contínuo cuidado e investimento. Quando pensamos na alfabetização plena, que deveria ser de direito e alcance para todos, olhamos para a sala de aula como um espaço no qual toda a potencialidade infantil oferece a chance de ser explorada, desde que abertos e explorados os recursos adequados.

Esta investigação aborda pontos para analisar o investimento na formação de sujeitos capazes de produzir textos e de analisar escritas produzidas por outros. Assim, tomamos um projeto didático de reescrita de um conto tradicional, com a proposta de inserção de uma modificação, realizado por crianças de $2^{\circ}$ ano de uma escola particular da cidade de São Paulo, Brasil, para propor uma interação entre turmas distintas. O projeto em questão é parte do currículo previsto pela escola analisada.

A investigação também colocou em cena um contexto no qual leitura e escrita se materializam por meio de suportes específicos: os meios digitais. As produções foram realizadas no processador de textos online Google Docs, ou seja, além dos textos terem sido realizados diretamente por meio de um computador, a revisão também ocorreu diretamente "em tela", e não "em papel”, o que gerou desafios específicos.

São muitos os investigadores que atualmente têm refletido sobre a questão do uso de meios digitais dentro da escola, analisando quais são as questões necessárias para o investimento em um

\section{plurais}


trabalho no qual a tecnologia atual não seja simplesmente a finalidade, mas também o meio que proporcione a relação dos alunos com o conhecimento. Neste sentido, por exemplo, Perelman (2014) e Kriscautzky (2014) vêm analisando as novas formas de uso de meios digitais para a obtenção de informação, por exemplo, com o apoio de buscadores de internet, discutindo como o seu uso coloca em jogo novas necessidades didáticas da relação dos alunos com estas fontes de informação.

Além disso, assumimos a perspectiva centrada na compreensão de que produzir textos é pensar em práticas comunicativas complexas, relacionadas com as práticas de linguagem de oralidade, leitura e escrita, e nas quais é preciso considerar que fundamentalmente assume-se a posição de que um texto não é finalizado em uma primeira escrita. Isto torna-se mais evidente quando tratamos de crianças em início de escolaridade, com experiências todavia iniciais como leitoras e escritoras, e que mostram em seus textos as esperadas questões em construção a respeito do sistema de escrita e dos aspectos discursivos.

Este panorama estabelece claramente a importância da revisão de textos como recurso para as retomadas das produções e assim garantir que seja possível avançar tanto no sentido do texto em si, que amplie sua qualidade, quanto na aprendizagem daquele que produz e revisa, o aluno, sujeito cognoscente. É fundamental considerar para este processo o olhar da revisão de textos apresentado por Castedo (2003):

Llamaremos revisión de textos a toda reconsideración de una primera textualización, incluyendo tanto los comentarios, opiniones y críticas de autores y lectores como las alteraciones efectivas realizadas sobre el escrito. Denominaremos reescrituras a estas alteraciones efectivas (p. 1, grifos da autora).

A complexidade do tema fica evidente quando pensamos na formação inicial leitora e escritora das crianças, e ganha ainda mais relevância quando consideramos os percursos de investigações realizadas nos últimos anos (destacando-se, além de CASTEDO, 2003; GALABURRI, 2004 e PELÁEZ, 2016), sobre o papel da revisão de textos para a formação do escritor e do leitor. Estas novas investigações destacaram o papel comunicativo da revisão de textos, a complexidade da diferenciação entre leitor e escritor; o revisar como uma ação de avanços progressivos; a varie-

\section{plurais}

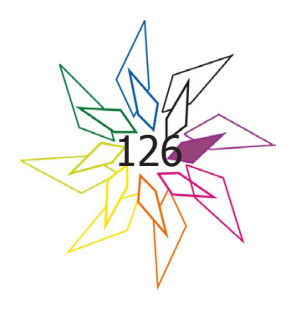


dade de estratégias para revisar um texto e, tema central desta investigação, a potencialidade da interação para a revisão.

\section{Contexto da investigação}

A presente investigação parte da análise de uma situação didática bastante específica dentro da instituição na qual realizou-se o trabalho a ser focalizado: a proposição de um projeto didático em classes de $2^{\circ}$ ano do Ensino Fundamental 1, relacionado com a reescrita com pequenas modificações de um conto de fadas. Os contos foram reescritos em duplas após diferentes leituras e uma primeira revisão foi realizada antes de alcançarem o momento específico aqui analisado: a leitura por parte de uma dupla de alunos de um $2^{\circ}$ ano, do texto reescrito por outra dupla de $2^{\circ}$ ano, com a inserção de comentários sobre necessidades de melhorias no texto.

O objetivo da investigação foi analisar quais conteúdos as crianças, imersas neste percurso intenso de um projeto didático, acabam por trabalhar no momento de fazer comentários em textos escritos por seus colegas. Também busca-se investigar os diferentes desafios colocados pela realização desta tarefa por meio de uma ferramenta digital de comunicação, como é o caso dos comentários do Google docs, editor de textos do Google drive, ferramentas bastante utilizadas na instituição na qual se desenvolve a investigação. Também analisou-se a relação entre os comentários escritos pelas crianças e o uso deles pelos autores do texto para a revisão de suas produções, juntamente com todo o conjunto de trocas orais estabelecidas durante este processo.

Neste sentido, as perguntas importantes que orientam o trabalho são:

- Conteúdos linguísticos em jogo: quais são os que as crianças conseguem selecionar para comentar? Conseguem justificar o que observam?

- Estratégias comunicativas: como as crianças inserem, ou não, recursos para melhor comunicar-se por escrito com os autores do texto? De que maneira conseguem colocar suas ideias sobre possíveis necessidades de ajustes?

Escolheu-se para esta investigação uma escola particular da zona oeste de São Paulo, capital, cidade brasileira que conta com um trabalho de referência tanto no âmbito de práticas de lingua-

\section{plurais}


gem da perspectiva aqui considerada, do construtivismo latino-americano ${ }^{1}$, como na proposição de situações que aproximem as crianças do uso de meios digitais, ou seja, nos interessava que os alunos envolvidos não tivessem uma experiência inaugural com ferramentas tecnológicas, mas sim que pudessem ter familiaridade com algumas delas. Vale destacar, no entanto, que a experiência do grupo selecionado com a ferramenta de comentários do Google docs ainda não era vasta.

Para a investigação acompanhou-se o trabalho de duas classes diferentes da mesma escola, porém de unidades localizadas em bairros distintos. As classes são conduzidas por duas professoras diferentes, ambas bastante experientes na escola. Uma das classes, aqui chamada CLASSE A, contava com 26 alunos, tendo então 13 duplas para o trabalho de reescrita, e outra classe, chamada CLASSE B, contava com 27 alunos, tendo 12 duplas e um trio de trabalho para o projeto. Foram selecionadas 3 duplas da CLASSE A e 3 duplas da CLASSE B, sendo o foco de análise o impacto dos comentários feitos das duplas da CLASSE B aos textos da CLASSE A. As crianças tinham no momento da pesquisa entre 7 e 8 anos de idade e estavam no $2^{\circ}$ ano do chamado Fundamental 1 , que no Brasil é o ciclo que se inicia após a etapa da Educação Infantil.

Conforme mencionado, a investigação toma como ponto de análise um projeto realizado na instituição, nas salas de $2^{\circ}$ ano. A CLASSE A decidiu trabalhar com "Três laranjas mágicas", conto no qual as crianças deveriam inserir mais um objeto encantado a ser oferecido pela bruxa, antes do objeto final. A CLASSE B optou pelo conto "Mãe Nevada", com a inserção de mais um objeto que precisaria receber a bondosa ajuda da protagonista. A partir dos contos reescritos em cada turma, era necessário estabelecer uma forma de seleção dos textos e para isso organizou-se previamente uma prova piloto que permitiu orientar as decisões tomadas.

Decidiu-se, então, que, entre os 6 textos que em cada classe seriam produzidos de cada um dos contos selecionados (um por dupla), 3 deles seriam tomados para a coleta dos dados buscados. Seriam considerados para a escolha dos textos (e consequentemente dos alunos) os acordos feitos em sala no processo prévio vivenciado antes da realização dos comentários que foram, reescrever um texto garantindo a presença de todos os episódios centrais da narrativa e inserir a modificação

1 Tal escola trabalha desde sua fundação, em 1980, com as pesquisas realizadas por Emília Ferreiro e Ana Teberosky sobre a psicogênese da linguagem escrita, sendo portanto referência no trabalho construtivista latino-americano em São Paulo. Realiza diversas formações internas e possui um centro de formação que atua oferecendo propostas que deem conta de práticas de referência para professores de todo o Brasil.

\section{plurais}

Salvador, v. 5, n.3, p. 122-143, set./dez. 2020 
proposta pela professora conseguindo utilizar recursos discursivos que tornassem a inserção como parte coerente do texto como um todo.

A partir destes acordos selecionaram-se os textos que tinham cumprido a maior parte dos acordos coletivos, os textos que cumpriram parte dos acordos, e textos que estavam abaixo dos acordos coletivos. Com isso organizou-se a dupla de uma classe que comentaria o texto da outra classe, buscando proximidade em relação aos saberes que colocaram em jogo no processo de reescrita.

Conforme já mencionado, os dados analisados na investigação dão conta não apenas dos textos escritos pelos alunos, bem como de seus comentários escritos utilizando a ferramenta do Google docs, apropriada para estas inserções. Também contempla as trocas orais realizadas pelas duplas de crianças no momento da análise do texto de seus colegas. Para isso utilizou-se a ferramenta Atube catcher, que gerou arquivos de vídeo da tela de trabalho das duplas de crianças produtoras de texto, bem como do áudio das conversas realizadas, assim como das entradas da entrevistadora.

Assim, o conjunto de elementos analisados é composto por:

1) Textos produzidos por alunos da CLASSE A, com os comentários dos alunos da CLASSE $B$, e as consequentes revisões;

2) As transcrições das trocas orais realizadas pelos alunos, ao realizarem os comentários escritos;

3) Gravações em vídeo das telas dos computadores utilizados pelos alunos durante esta situação.

\section{Revisar, comentar e interpretar por escrito.}

Em uma primeira análise ampla do que foi possível obter da situação investigada, temos os seguintes dados com relação às ações das crianças ao comentar e revisar seus textos: 
Tabela 1: Organização geral dos dados quantitativos de comentários e quantidade de alterações feitas nos textos

\begin{tabular}{|l|l|l|l|}
\hline \multicolumn{1}{|c|}{ Comentaristas $^{2}$} & $\begin{array}{l}\text { Quantidade de } \\
\text { comentários }\end{array}$ & \multicolumn{1}{c|}{ Autores $^{3}$} & $\begin{array}{c}\text { Quantidade de altera- } \\
\text { ções realizadas no texto }\end{array}$ \\
\hline Olga e Letícia (COM_1B) & 14 & $\begin{array}{l}\text { Denis e Caio } \\
\text { (AUT_1A) }\end{array}$ & 10 \\
\hline $\begin{array}{l}\text { Bruna e Eleonora } \\
\text { (COM_2B) }\end{array}$ & 11 & $\begin{array}{l}\text { Lucas e Laura } \\
\text { (AUT_2A) }\end{array}$ & 9 \\
\hline $\begin{array}{l}\text { Iara e André } \\
(\mathrm{COM} 3 \mathrm{~B})\end{array}$ & 7 & $\begin{array}{l}\text { Paulo e Tomás } \\
\text { (AUT_3A) }\end{array}$ & 10 \\
\hline
\end{tabular}

Fonte: Elaborado pelas autoras a partir dos dados da investigação

Ainda que a investigação que aqui se apresenta não seja pautada em análises quantitativas, este primeiro olhar numérico já mostra a escala crescente de comentários de acordo com a categorização das duplas, ou seja, aquelas do grupo 1, que contemplaram a maior parte dos acordos coletivos, escreveram mais comentários que as dos grupos seguintes. O mesmo não ocorre na quantidade de alterações, que não mostra uma relação crescente direta a depender do grupo ao qual pertencem os autores do texto, ou seja, todos foram capazes de corrigir seus textos.

Também é possível notar que não há uma relação direta entre comentário e alteração no texto, no sentido de que não necessariamente um comentário gerou sempre alguma modificação, inclusive, no caso da produção de Paulo e Tomás (AUT_3A), a quantidade de pontos do texto que tiveram alguma alteração é superior à quantidade de comentários recebidos.

2 Os comentaristas foram nomeados com a sigla COM seguida de 1, 2 ou 3 a depender da seleção inicial dos textos. As duplas indicadas com 1 referem-se às crianças que conseguiram cumprir a maior parte dos acordos coletivos, as duplas 2 são das crianças que cumpriram uma parte dos acordos, e o número 3 foi dado às crianças que ficaram abaixo dos acordos coletivos. A letra $\mathrm{B}$ refere-se à classe que fazem parte, no caso CLASSE B.

3 Assim como no caso dos comentaristas, os autores também foram nomeados com uma sigla, no caso, AUT, seguindo depois a mesma organização explicada nos comentaristas: os números referem-se à classificação de seus textos em relação aos acordos coletivos, e a letra A refere-se a serem parte da CLASSE A.

\section{plurais}

Salvador, v. 5, n.3, p. 122-143, set./dez. 2020 
Os dados numéricos iniciais, ao serem complementados com a leitura geral do conjunto de comentários, permitiu organizá-los em duas categorias que aqui chamaremos de comentários diretos e comentários indiretos. Vejamos como entender esta organização.

Um conjunto de comentários mostrou ter como característica central a presença de indicações específicas e pontuais para os autores do texto daquilo que deveriam modificar em suas produções. A tabela abaixo mostra exemplos de comentários diretos, presentes nas três duplas:

Tabela 2: Exemplos de comentários diretos realizados pelas duplas de alunos.

\begin{tabular}{|c|c|l|}
\hline Olga e Letícia (COM_1B) & Bruna e Eleonora (COM_2B) & Iara e André (COM_3B) \\
\hline $\begin{array}{l}\text { (12.1B) Tem acariciando invés de } \\
\text { carinho }\end{array}$ & (1.2B) Tem que ter era uma vez & $\begin{array}{l}\text { (7.3B) Tem duas palavras } \\
\text { repetidas }\end{array}$ \\
\hline
\end{tabular}

Fonte: Elaborado pelas autoras a partir dos dados da investigação.

Nestes casos foi possível notar uma intervenção direta na produção, no sentido de anunciar uma alteração específica para a revisão, e por isso foram considerados como comentários diretos para os autores do texto. Além disso, os exemplos acima mostram uma característica que se manteve em todos os comentários feitos pela CLASSE B: ainda que com uma indicação direta, em nenhum caso utilizaram unicamente uma palavra para a menção aos autores (por exemplo, escrever apenas "acariciando" no caso do comentário 12.1B), vindo sempre acompanhados de uma estrutura discursiva ("tem que..."; "precisa"; "poderia"), algo que constatamos que acompanhou parte das discussões dos alunos comentaristas.

Outro tipo de comentário, menos frequente nas duplas, mas ainda assim importante de ser analisado por sua presença em todos os agrupamentos, foi aquele que necessariamente implicava uma interpretação maior por parte dos autores do texto, para que fosse gerada alguma revisão textual:

Tabela 3: Exemplos de comentários indiretos realizados pelas duplas de alunos.

\begin{tabular}{|l|l|l|}
\hline \multicolumn{1}{|c|}{ Olga e Letícia (COM_1B) } & \multicolumn{1}{|c|}{$\begin{array}{c}\text { Bruna e Eleonora } \\
\text { (COM_2B) }\end{array}$} & \multicolumn{1}{|c|}{ Iara e André (COM_3B) } \\
\hline $\begin{array}{l}\text { (7.1B) Eles se casaram no mesmo } \\
\text { dia e na mesma hora? }\end{array}$ & $\begin{array}{l}\text { (11.2B) Tomem mais cuidado } \\
\text { com as letras }\end{array}$ & $\begin{array}{l}\text { (6.3B) Faltou colocar uma } \\
\text { parte }\end{array}$ \\
\hline
\end{tabular}

Fonte: Elaborado pelas autoras a partir dos dados da investigação

\section{plurais}


É possível notar que os comentários não oferecem neste caso um direcionamento pontual de qual ação revisora deveria ser realizada no texto, ou seja, seria necessária uma tomada de decisão ampliada por parte dos autores (usamos o termo «ampliada», pois mesmo os comentários diretos levaram à necessidade de uma decisão, se seguir ou não o direcionamento apresentado). Este tipo de comentário foi chamado de comentário indireto.

No acompanhamento das conversas mantidas pelos alunos comentaristas não foi possível perceber referências consistentes das decisões desta diferenciação, mas um trecho de uma conversa mantida pela dupla Iara e André (COM_3B) na escrita de um comentário indireto permite vislumbrar um olhar que aponta a este controle nas indicações oferecidas":

$$
\begin{aligned}
& \text { André - faltou colocar uma // parte } \\
& \text { Iara- qual é essa parte (?) } \\
& \text { André - eu não vou dizer / eles quem tem que descobrir }
\end{aligned}
$$

Os comentários indiretos também mantêm a característica que mencionamos quanto aos comentários diretos, de serem compostos por pequenas frases e orações, e não por palavras isoladas, indicando claramente a preocupação das crianças no uso de recursos comunicativos na interlocução com os colegas.

Além desta diferença no tipo de comentário, foi possível realizar uma comparação sobre o impacto destes pequenos textos nos autores do texto. Para isso, três consequências diferentes foram identificadas, no momento da revisão:

\footnotetext{
4 Utilizamos los criterios de transcripción de la oralidad que sugiere Blanche-Benveniste (1998). No incluimos mayúsculas, sino sólo para indicar nombres propios; no utilizamos signos de puntuación como se utilizan convencionalmente en la escritura y recurrimos al siguiente código para expresar algunas características propias de los intercambios orales:

/ pausa corta

// pausa larga

? y ! al final de una cláusula para enfatizar su carácter interrogativo o exclamativo

..... para indicar supresiones en una secuencia dialógica

() para intercalar comentarios o aclaraciones sobre lo que ocurre durante la entrevista, como por ejemplo, para indicar que el niño lee en voz baja o en voz alta. (Blanche-Benveniste, 1998, p. 63)
}

\section{plupais}

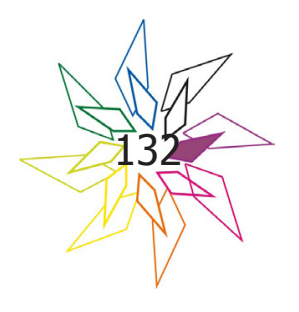


• Comentários aceitos pelos autores: neste caso a mesma alteração indicada foi realizada na produção;

- Comentários que levaram a uma modificação no texto, não necessariamente a mesma indicada pelos comentaristas;

- Comentários que não geraram qualquer modificação no texto.

Vejamos então como essas possibilidades materializaram-se na investigação:

Tabela 4: Relação entre a quantidade de comentários diretos e o tipo de alteração que ocasionaram no texto após revisão das crianças.

\begin{tabular}{|c|c|c|c|c|}
\hline \multicolumn{5}{|c|}{ Comentários diretos } \\
\hline $\begin{array}{c}\text { Duplas de comen- } \\
\text { taristas }\end{array}$ & Total & $\begin{array}{c}\text { 1) Modificação idêntica } \\
\text { à sugerida }\end{array}$ & $\begin{array}{c}\text { 2) Modificação diferente } \\
\text { da sugerida }\end{array}$ & $\begin{array}{c}\text { 3) Nenhuma } \\
\text { modificação }\end{array}$ \\
\hline $\begin{array}{c}\text { Olga e Letícia } \\
\text { (COM_1B) }\end{array}$ & H8 & 5 & 1 & 2 \\
\hline $\begin{array}{c}\text { Bruna e Eleonora } \\
\text { (COM_2B) }\end{array}$ & 9 & 7 & 1 & 1 \\
\hline $\begin{array}{c}\text { Iara e André } \\
\text { (COM_3B) }\end{array}$ & 4 & 4 & - & - \\
\hline
\end{tabular}

Fonte: Elaborado pelas autoras a partir dos dados da investigação

Tabela 5: Relação entre a quantidade de comentários indiretos e o tipo de alteração que ocasionaram no texto após revisão das crianças autoras do texto.

\begin{tabular}{|c|c|c|c|}
\hline \multicolumn{3}{|c|}{ Comentários indiretos } \\
\hline $\begin{array}{c}\text { Duplas de comenta- } \\
\text { ristas }\end{array}$ & Total & $\begin{array}{c}\text { Comentários aceitos (levaram } \\
\text { a uma modificação no texto) }\end{array}$ & $\begin{array}{c}\text { Comentários não aceitos } \\
\text { (nenhuma modificação é reali- } \\
\text { zada no texto) }\end{array}$ \\
\hline $\begin{array}{c}\text { Olga e Letícia } \\
\text { (COM_1B) }\end{array}$ & 66 & 3 & 3 \\
\hline $\begin{array}{c}\text { Bruna e Eleonora } \\
\text { (COM_2B) }\end{array}$ & 22 & 1 & 2 \\
\hline $\begin{array}{c}\text { Iara e André } \\
\text { (COM_3B) }\end{array}$ & 33 & 1 & 1 \\
\hline
\end{tabular}

Fonte: Elaborado pelas autoras a partir dos dados da investigação 
Estes dados gerais mostram que os comentários diretos ocasionaram que grande parte das indicações levasse a modificações por parte dos autores do texto, enquanto que os comentários indiretos mostram maior equilíbrio entre comentários aceitos e não aceitos, o que indica uma maior dificuldade para as crianças interpretarem os comentários e conseguirem realizar uma modificação em sua produção. Vale destacar que no caso da análise dos comentários indiretos não temos modificações feitas que são diferentes daquelas consideradas pelos comentaristas na hora de inserir sua contribuição (como sim ocorreu nos comentários diretos, modificações de tipo 2, nas quais há uma revisão, mas não a sugerida), ou seja, ou decidiam modificar algo no texto, em alguns casos conseguindo compreender a sugestão indireta de seus colegas, ou acabavam por simplesmente descartar o comentário recebido.

Outro ponto a destacar é o fato de que estes dados gerais mostram uma realização da proposta bastante equilibrada entre as diferentes duplas; ainda que a dupla do grupo 1 tenha realizado uma maior quantidade de comentários, tanto a dupla do grupo 2 quanto do grupo 3 apresentam uma presença constante de comentários, tanto diretos quanto indiretos, e mesmo um cuidado com a linguagem na produção deles, já que, como indicamos, todos escreveram usando uma organização textual, não restrita a palavras isoladas.

Compreender mais profundamente os dados por ora apresentados é fundamental para a reflexão sobre as possibilidades destes leitores e escritores inexperientes diante de uma proposta complexa. Neste sentido, utilizaremos o conceito de espaços textuais, apresentado por Ferreiro e Luquez (2003), para entender o processo acompanhado por esta investigação. As autoras optam por uma nova forma de analisar os textos:

La categorización construida para dar cuenta de las intervenciones de los niños remite a un análisis de los textos originales, en donde distinguimos espacios textuales de intervención, y a las modificaciones producidas en ellos, que llamaremos modos de intervención. Cada intervención del revisor se ubica, entonces, en cierto espacio textual (¿dónde interviene?) y, simultáneamente, en relación con el modo de intervención elegido (¿cómo interviene?). Esta descripción inicial permitió caracterizar las intervenciones de los revisores sin adjudicar desde el comienzo una finalidad a cada una de ellas (FERREIRO e LUQUEZ 2003, p. 3).

As autoras complementam a apresentação desta categorização colocando que

\section{plurais}


Los espacios textuales son fragmentos de los textos originales que remiten a partes identificables de la historia, a veces coincidentes con los episodios y en ocasiones subdivisiones de los episodios. Como espacios textuales de intervención son específicos de cada uno de los textos presentados a revisión (FERREIRO e LUQUEZ, 2003, p.3).

Desta forma, pensando que efetivamente a ação aqui analisada não se relaciona apenas com possíveis correções do texto, que, ainda segundo Luquez e Ferreiro, são unicamente as revisões feitas pelos próprios autores do texto, torna-se pertinente pensar nestas entradas escritas como intervenções na produção que deveriam analisar. Ao receberem os textos na íntegra as crianças tiveram que decidir os pontos no texto nos quais iriam inserir suas contribuições, e isto nos oferece a possibilidade de observar a maior ou menor frequência de intervenções nos diferentes espaços do texto e assim obter um parâmetro que permita entender os modos de realizar esta intervenção.

Assim, pensando nos espaços textuais com mais intervenções e menos intervenções, foi possível observar que o espaço textual selecionado por sua grande frequência de intervenções dos comentaristas foi aquele marcado por uma estrutura de repetição. Assim, ainda que o conto comentado como um todo não tenha uma estrutura repetitiva, o trecho em questão possui esta marca específica, que o coloca como um espaço textual com bastante potencialidade para receber as intervenções dos alunos, e que realmente acaba favorecendo a concentração de comentários, uma vez que estas repetições claramente favoreceram a apropriação do texto por parte dos comentaristas. A análise das intervenções neste espaço textual mostra que as duplas selecionaram quatro focos para a escrita de comentários: Inserção de fragmentos, repetição de palavras; pontuação e vocabulário.

A seleção de cada comentário realizado dentro destes âmbitos mostrou, pelas trocas orais e ações realizadas em tela, um intenso processo até a decisão final, do que seria oferecido como contribuição aos colegas. O trecho abaixo mostra o processo delicado desta elaboração:

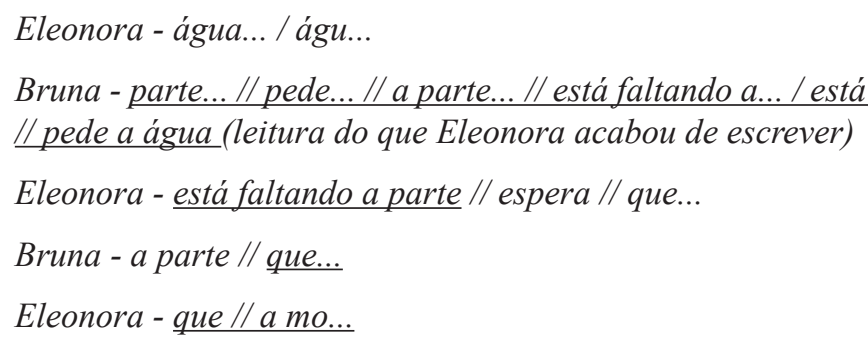


Bruna - a moça

Eleonora - a mo... //

Bruna - que a moça

Eleonora - pede

Bruna - espera ai

Eleonora - a moça pede a água

Bruna - está faltando a parte // que a...

Eleonora - a moça pede a água

Bruna - pede // a moça pede a água / ai / agora entendi

Eleonora - comentar / prontinho

Já logo no começo do diálogo Bruna atua como leitora do que Eleonora está registrando e isso favorece a percepção de que a escrita daquele momento "está faltando a parte pede a água" precisa de ajustes. Neste percurso de escrita do comentário as alunas precisam lidar com diferentes estruturas textuais, por um lado está o que lembram do trecho do conto original, ("lhe pediu um gole de água"), por outra parte a menção em voz alta constante das alunas "a parte da água" e a textualização do comentário em si, com sua estrutura própria. Nesta versão final elas colocam um marcador claro de pertinência do comentário (a palavra "faltando", ou seja, indicando ausência), bem como uma menção objetiva para os autores do que deveriam modificar, "parte pede a água".

Da mesma forma, e reforçando a complexidade da situação proposta às crianças, mesmo quando decidem rápido o que comentar, o processo de escrita e uso dos recursos digitais também explicitam processos variados até a realização final do comentário, algo que podemos identificar no caso de Olga e Letícia. Elas vivem um processo no qual chegam a um acordo relativamente rápido sobre a importância de inserir um comentário a respeito do desenrolar de ações da terceira moça, já que diante do trecho:

saiu uma moça de cabelo preto e com rosto de jasmim:

- Um gole de água por favor

Ocorre a rápida constatação:

\section{plurais}

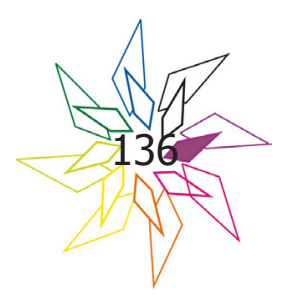


Olga - espera / para / rapidinho / aqui / espera ai // "e ela pediu..." / podia ser / "e ela pediu um gole de água / por favor" / porque também / eu... / assim... // "e com rosto de jasmim // um gole de água / por favor"

Letícia - ela pediu

$O \lg a-e^{5}$

Porém, mesmo com clareza sobre a necessidade de uma intervenção, Letícia e Olga encontram novos obstáculos para pensar na organização textual desta comunicação por escrito aos autores do texto. Na tabela a seguir estão listadas as ações realizadas pelas alunas até produzirem o comentário final, tanto com relação ao que grifaram para abrir a caixa de comentários quanto para o texto em si do que diriam aos colegas.

Tabela 6: Organização dos diferentes comentários escritos realizados pelas comentaristas do texto.

\begin{tabular}{|c|c|c|}
\hline Ações realizadas & Trecho grifado & Comentário escrito \\
\hline $1^{\mathrm{a}}$ ação & - Um gole de água por favor & "a moça poderia ter" \\
\hline $2^{\mathrm{a}}$ ação & - Um gole de água por favor & $\begin{array}{l}\text { apagam "a moça" e deixam "poderia } \\
\text { ter" }\end{array}$ \\
\hline $3^{\mathrm{a}}$ ação & - Um gole de água por favor & apagam todo o comentário \\
\hline $4^{\mathrm{a}}$ ação & \multicolumn{2}{|l|}{ Apagam todo o grifo } \\
\hline $5^{\mathrm{a}}$ ação - Comentário final & jasmim & $\begin{array}{l}\text { "depois de jasmim poderia ter e ela } \\
\text { pediu" }\end{array}$ \\
\hline
\end{tabular}

Fonte: Elaborado pelas autoras a partir dos dados da investigação

Podemos perceber que ainda que a tarefa proposta para as alunas tenha como resultado uma escrita curta, "depois de jasmim poderia ter e ela pediu”, não é a pequena extensão textual o

\footnotetext{
5 Vemos aqui que ainda que o texto que estão comentando tenha a presença do travessão, que dispensaria, desta forma, a indicação explícita de que teria sido feito um pedido, Letícia e Olga decidem por comentar sobre a necessidade de explicitar o discurso direto, por isso comentando sobre a necessidade de inserir "ela pediu". Vemos, então, que nem sempre o comentário realizado mostra maior complexidade de análise textual do que o texto analisado, mas que ainda assim mostra-se relevante para o processo de aprendizagem ao colocar diferentes desafios às alunas durante a elaboração da intervenção (ler, analisar, decidir o comentário e escrevê-lo).
} 
reflexo completo do processo vivido, que envolveu leitura, troca oral e escrever e reescrever até chegar ao comentário final.

Com relação ao espaço textual com menos comentários destacamos o de fechamento do texto, no qual é feita a narrativa do desenlace da bruxa. O final da narrativa do conto "As três laranjas mágicas" deixa claro o estado de felicidade dos protagonistas, mas menciona de forma vaga que ao buscarem a cabana da bruxa só encontraram: "cinzas e um rolo de fumaça escura que parecia uma forma humana” (PHILIP, 1998, p. 43).

O acompanhamento do percurso vivido pelas duplas mostra que das três duplas apenas uma aborda diretamente o relato da finalização sobre a bruxa, e a outra dupla que faz o comentário neste espaço focaliza em questões de repetição de palavras e não na organização discursiva do trecho de um texto que sim poderia ter um relato mais detalhado. $O$ fato do texto não explicitar de forma clara o que teria acontecido com a bruxa, constituindo então um final quase em aberto, apresenta o desafio de interpretação a crianças que estão mais habituadas a finais mais fechados, já que esta é uma característica muito marcante em grande parte dos contos tradicionais. Isto situa este espaço textual como um ponto que poderia dificultar a realização de intervenções, já que o controle dos acontecimentos por parte dos próprios leitores depende da relação com um relato bastante peculiar dentro do gênero.

Para além desta questão da diferença dos espaços com mais ou menos intervenções por parte dos comentaristas, a análise dos processos envolvidos em ambos os casos permitiu identificar que a ação de comentar um texto alheio proporcionou que as crianças colocassem em jogo importantes ações leitoras e escritoras, fundamentais para qualquer usuário das práticas de linguagem. Entre elas, destacamos:

- Leitura cuidadosa do texto analisado, buscando compreender o sentido construído - ou não - pelos autores do texto;

- Discussão oral sobre o que deveriam selecionar para realizar uma intervenção no texto, tanto do ponto de vista do trecho no qual originar o comentário quanto da pertinência de realizar uma intervenção ou não;

- Manejo da ferramenta tecnológica utilizada para realizar a produção escrita;

\section{plurais}

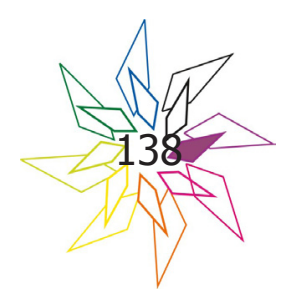


- Elaboração escrita do comentário selecionando palavras e expressões adequadas de forma a conseguir uma comunicação eficiente daquilo que desejavam compartilhar;

- Atuação como escribas e ditantes enfrentando diferentes desafios leitores e escritores;

- Releituras constantes da escrita do comentário, elaborando possíveis ajustes;

- Argumentação oral constante para fundamentar suas opiniões.

No caso dos revisores do texto o processo claramente é mais dinâmico e a proposta encerra-se mais rápido, se comparado ao processo dos comentaristas, o que não quer dizer que não vivem intensos momentos de aprendizagem. Isso fica explícito na constatação de que mesmo quando recebem comentário diretos, as trocas orais mostram a potencialidade deste espaço de troca com um leitor alheio.

Laura e Lucas, por exemplo, observam o comentário direto "está faltando a parte que a moça pede a água", algo que os autores parecem concordar rapidamente:

Lucas - eu estou contando / tem mais de um (refere-se à quantidade de comentários) / é (?) / você quer muito (?) // "está faltando a parte que a moça pe..."

Laura - "pede água”

Lucas - é / é verdade / olha

Laura-aonde (?) / “o ra...” verdade

Lucas - então / vai / vai / vai // água / olha / elas fizeram do lado errado / esse é o lado errado (apontando para a escrita de "faltando", que está registrada no comentário como "fal tando")

O processo de escrita, porém, não é linear, mas sim leva os alunos a produzirem algumas versões em sua revisão:

Tabela 7: Organização das diferentes modificações realizadas pelos autores do texto durante a revisão, a partir do trecho no qual receberam um comentário.

\begin{tabular}{|l|l|l|}
\hline \multicolumn{1}{|c|}{ Ações } & \multicolumn{1}{|c|}{ Inserção } & \multicolumn{1}{c|}{ Como fica o trecho } \\
\hline $\mathbf{1}^{\mathbf{a}}$ ação & água & "cor vermelho água ele não pôde" \\
\hline $\mathbf{2}^{\mathbf{a}}$ ação & um copo de água & "cor vermelho um copo de água ele não pôde" \\
\hline $\mathbf{3}^{\mathbf{a}}$ ação & a moça pediu um copo de água & $\begin{array}{l}\text { "cor vermelho a moça pediu um copo de água ele não } \\
\text { pôde" }\end{array}$ \\
\hline
\end{tabular}

Fonte: Elaborado pelas autoras a partir dos dados da investigação 
O acompanhamento deste percurso mostra que Laura e Lucas realizam as inserções do final da frase para o começo, ou seja, ao invés de começarem pela escrita de "a moça", seguindo com a ação, começam por "água" e inserem o que é anterior a isso, algo que alcançam por meio das releituras. A transcrição para a realização da $3^{\mathrm{a}}$ ação mostra como o processo de inserir algumas poucas palavras envolve uma troca intensa:

$$
\begin{aligned}
& \text { Laura - vermelha } \\
& \text { Lucas - "co... / um..." } \\
& \text { Laura - "vermelho / um copo de água / ele não pôde..." } \\
& \text { Lucas - olha / acho que pôs no errado } \\
& \text { Laura - onde (?) } \\
& \text { Lucas - "vermelho / copo... / um copo de água" (?) / hum }
\end{aligned}
$$

Entrevistadora - "saiu uma moça de olhos da cor verdes e cabelos da cor vermelho / um copo de água (...)”

Laura - não sei

Lucas - isso eu não sei / me desculpa

Entrevistadora - o que está errado / Lucas (?)

Lucas - eu estou sentindo alguma coisa / mas onde põe o espaço (?)

Entrevistadora - aqui / olha (aponta para a barra de espaço do teclado)

Laura - "um copo de água / por favor" / está escrito II "a moça pediu..."

Lucas - tem que ter o espaço (aperta a barra de espaço após a palavra "vermelho" e escreve "a moça pediu")

Laura - "um copo de água"

Lucas - pronto

Assim, no caso dos revisores, observamos que ocorrem processos leitores e escritores, alguns semelhantes ao realizados pelos colegas que enviaram comentários em seu texto, e outros distintos. Eles também realizam, como os comentaristas, discussões orais importantes para decidir se, e o que revisariam; também precisam lidar com o manejo da ferramenta tecnológica, inserindo os trechos revisados diretamente no computador, bem como também fazem releituras constantes, neste caso do texto modificado a partir das contribuições realizadas. A grande diferença está na leitura, já que o que orienta os revisores não é a leitura do texto na íntegra, como ocorre com os comentaristas, mas

\section{plurais}


sim a dos comentários, ou seja, eles orientam a leitura ao observarem uma intervenção dos colegas e, a partir dela, fazem leituras dos trechos do texto comentado.

\section{Conclusões}

Nossa investigação procurou compreender, dentro de suas possibilidades e consequentes limitações, como um desafio desconhecido pelos alunos de $2^{\circ}$ ano, a realização de comentários por escrito em um texto de outros colegas, poderia potencializar suas reflexões sobre a língua escrita. O acompanhamento das vivências de 12 crianças de 7 e 8 anos de idade oferece alguns indícios relevantes que comprovam o quanto olhar e analisar outro texto, que não o próprio, sim permite colocar em jogo uma variedade de recursos leitores e escritores importantes para a formação dos alunos e alunas.

A partir de todas as análises realizadas podemos concluir que ter o desafio de comentar o texto escrito por outro colega, sendo inclusive um texto diferente daquele produzido por si mesmo, é uma proposta possível desde que garantidas condições específicas nas quais as crianças estejam imersas em um contexto de leituras e escritas com sentido e significado. Também podemos perceber que esta proposta não é unicamente uma tarefa pontual, na qual basta observar o texto e comentar; para realizá-la é preciso ler muito além do texto em si, e muita escrita se mobiliza para além daquela que será lida pelos autores do texto. Também notou-se que, mesmo com uma diferença de qualidade entre as produções iniciais, todas as duplas conseguiram mobilizar uma diversidade de saberes de enorme riqueza para o processo de formação leitora e escritora. Isto confirma o que tantas investigações apontam: de que a produção final de uma criança não contempla a totalidade de suas possibilidades e saberes, já que ler e escrever são processos complexos e nos quais entram em jogo conhecimentos que nem sempre são “concretizáveis" unicamente por meio de um texto.

Outro ponto importante da investigação relaciona-se ao uso de meios digitais. $\mathrm{O}$ fato deles terem sido inseridos contribuiu para a interlocução entre as crianças, já que, ao estarem distantes geograficamente, puderam trocar suas escritas entre si com grande agilidade; ao mesmo tempo é importante considerar que a mudança de um suporte implica considerar novos desafios e novas formas de realizar leituras e escritas. Este ponto reforça a necessidade de novas investigações sobre o uso de meios digitais, permitindo compreender ainda mais profundamente quais são os novos desafios enfrentados em sala de aula, que, unidos aos desafios habituais de leitura e escrita, trazem um contexto no qual é preciso adentrar-se para potencializar cada vez mais os espaços de aprendizagem.

Com relação ao suporte essencial utilizado na investigação para compreendermos melhor as ações infantis, a oralidade, percebemos que é possível ampliar consideravelmente os caminhos a serem 
percorridos com este tema, por vezes relegado ao uso mais espontâneo e não analítico, dentro da escola. Ao buscarmos entender como estas trocas orais estabelecidas pelas palavras ditas, não necessariamente escritas, aconteceram, pudemos constatar que há muito mais aprendizagem para além do produto final. E que é função da escola conseguir cada vez mais aprofundar o olhar e garantir que as trocas orais tenham espaço e valor pedagógico, e não só espontâneo, no cotidiano escolar.

Ainda que seja um enorme desafio acompanhar e recuperar o oral, e que isso ofereça, como no caso desta investigação, um panorama complexo de análise de transcrições, é essencial poder seguir realizando esta reflexão de forma a ampliar a compreensão do processo que as crianças atravessam e no qual interferem fatores que por vezes não podem ser materializados por uma tecla ou um lápis, e que estão no que se diz e no que se escuta, e na relevância de terem espaço e tempo para este dizer, argumentar, ouvir e ponderar.

É fundamental, assim, que sigam-se construindo propostas didáticas que considerem um olhar processual para a produção textual. Os resultados desta investigação reforçam como escrever algo relativamente curto, de duas páginas, ou escrever um comentário ainda mais breve, de duas linhas, envolve complexos processos que devem ser planejados e organizados com cuidado. As situações aqui observadas na investigação foram acompanhadas, mapeadas, e, em sala de aula, se inseridas e consideradas pelos docentes, podem fomentar espaços de tematizações e ampliações que poderão apoiar a construção de saber por parte dos alunos e alunas de um grupo.

Destacamos especialmente a relevância da categorização de comentários diretos e indiretos e seus impactos na revisão textual. Foi possível notar a maior incidência do primeiro tipo de comentário, o direto, e a percepção de que ele é fonte de maiores possibilidades de interpretação e atuação revisora por parte dos autores do texto. Quando pensamos nos comentários indiretos, que, como vimos aqui, são mais abertos, e com muitos espaços interpretativos (consideremos, por exemplo, tudo que uma criança pode interpretar ao ler de seu colega o comentário “tomem mais cuidado com as letras"), é importante destacar que se concretiza uma dificuldade importante dos alunos na interpretação dos mesmos, ou seja, eles não se mostram frutíferos para o objetivo de alterações e entradas revisoras na produção textual.

Estes elementos não são apenas constatações, mas sim devem ser considerados de forma efetiva, juntamente com as inúmeras contribuições das investigações realizadas no âmbito da produção textual, para a elaboração, reflexão e até mesmo revisão das propostas didáticas em curso. Devemos constantemente avaliar e utilizar estas contribuições para realizar os ajustes didáticos necessários dentro da escola, que garantam, sempre, o avanço na aprendizagem de nossos alunos e alunas.

\section{plurais}

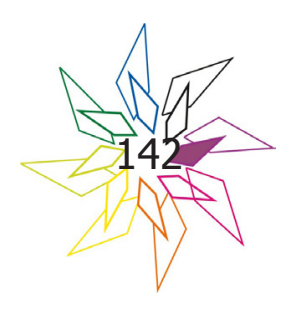




\section{REFERÊNCIAS}

BLANCHE-BENVENISTE, C. Estudios lingüísticos sobre la relación entre oralidad y escritura. Barcelona: Gedisa. 1998.

CASTEDO, Mirta. Procesos de revisión de textos en situación didáctica de intercambio entre pares. Tese (Doutorado). Tesis de Doctorado. Departamento de Investigaciones Educativas del Centro de Investigación y Estudios Avanzados del Instituto Politécnico Nacional. Cinvestav, México, 2003.

FERREIRO, Emilia; LUQUEZ, Sonia. La revisión de un texto ajeno utilizando un procesador de palabras. Revista Latinoamericana de Lectura (Lectura y vida), v. 24, n. 2, p. 50-61, 2003.

FREIRE, Paulo. Educação como prática da liberdade. Rio de Janeiro: Paz e terra, 1996.

GALABURRI, María Laura. La transformación de contenidos en la continuidad de las situaciones didácticas de revisión de textos. Dissertação (Mestrado). Facultad de Filosofía y Letras. Universidad de Buenos Aires, 2004.

KRISCAUTZKY, Marina. Seleccionar información en internet. Problemas y soluciones de los nuevos lectores ante la confiabilidad de las fuentes digitales de información. Tese (Doutorado) - Departamento de investigaciones educativas, CINVESTAV-IPN, 2014.

PELÁEZ, M.A. La transformación de contenidos abordados por los alumnos a través de situaciones didácticas de lectura, escritura y revisión de textos narrativos ficcionales. Tese (Doutorado). 2016. Universidad Nacional de La Plata. Facultad de Humanidades y Ciencias de la Educación.

PERELMAN, F.; ESTÉVEZ, V. Herramientas para enseñar a leer y producir en medios digitales. Buenos Aires: Aique, 2014.

TOLCHINSKY, Liliana. A aprendizagem da linguagem escrita. São Paulo: Ática, 1995.

Recebido em: 10 de julho de 2020.

Inserido em: 15 de outubro de 2020.

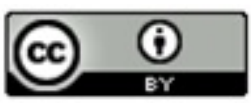

Esta obra está licenciada com uma Licença Creative Commons Atribuição 4.0 Internacional

\section{plurais}

